OPEN ACCESS

Edited by:

Kumiko Yoshihara,

National Institute of Advanced

Industrial Science and Technology

(AIST), Japan

Reviewed by:

Laura Ceballos,

Rey Juan Carlos University, Spain Pipop Saikaew,

Mahidol University, Thailand

*Correspondence:

Takaaki Sato

t.sato.ope@tmd.ac.jp

Specialty section: This article was submitted to

Dental Materials,

a section of the journal

Frontiers in Dental Medicine

Received: 10 February 2021

Accepted: 17 May 2021

Published: 22 June 2021

Citation:

Sato T, Takagaki T, Hatayama T, Nikaido T and Tagami J (2021) Update

on Enamel Bonding Strategies.

Front. Dent. Med. 2:666379.

doi: 10.3389/fdmed.2021.666379

\section{Update on Enamel Bonding Strategies}

\author{
Takaaki Sato $^{\text {1*}}$, Tomohiro Takagaki ${ }^{2}$, Takashi Hatayama ${ }^{1}$, Toru Nikaido ${ }^{2}$ and Junji Tagami ${ }^{1,2}$ \\ ${ }^{1}$ Department of Cariology and Operative Dentistry, Graduate School of Medical and Dental Sciences, Tokyo Medical and \\ Dental University (TMDU), Tokyo, Japan, ${ }^{2}$ Department of Operative Dentistry, Division of Oral Functional Science and \\ Rehabilitation, School of Dentistry, Asahi University, Gifu, Japan
}

Optimal strategies for the application of an adhesive differ between enamel and dentin because of the differences in their composition. The development of adhesive systems has mainly focused on the bonding of dentin, rather than on the enamel, by etching with phosphoric acid (PA). Dental adhesive technologies continue to rapidly advance, and various adhesive systems have been developed since the study of Buonocore in 1955. He introduced the enamel acid-etch technique. Then, the etch-and-rinse (ER) system was developed, and subsequently, the self-etch (SE) system. Universal adhesives are a new generation of one-bottle SE adhesives that can be applied with either ER mode or SE mode, or a combined system involving selective enamel etching mode. Since the combination of PA etching and the SE system differs from conventional ER systems, the enamel bonding strategy should be carefully considered. This concise review of the literature on reliable enamel bonding strategies should prove helpful to clinicians to choose an appropriate adhesive system to achieve optimal clinical outcomes.

Keywords: enamel, adhesive, phosphoric acid, universal adhesive, acid base resistant zone

\section{INTRODUCTION}

Adhesion largely determines the success or failure of composite resin (CR) restorations. Although various adhesive systems have been developed for reliable CR restorations (1-14), each product has unique characteristics that must be considered in clinical practice. Compared to dentin, adhesion to enamel was achieved at an early stage by etching the enamel surface with phosphoric acid (PA) (15). However, PA is too strong for the etching of dentin $(16,17)$. Dentin may be over-etched by PA; consequently, some part of the demineralized collagen layer is left uninfiltrated by bonding agents (17). Moreover, it has been considered that these incompletely infiltrated collagen fibrils in the over-etched dentin are susceptible to degradation by matrix metalloproteinases (18), which are activated by PA etching (19). To address this issue, selfetch (SE) systems for adhesion to both enamel and dentin without PA etching were developed, which are now used worldwide. Furthermore, the acidic functional monomer of the SE system allows for simultaneous etching and priming, which simplifies the clinical application. Although adhesive materials are user-friendly, etching ability with the acidic functional monomer of the SE system is milder than with PA. Therefore, an additional step, selective enamel etching, is recommended for mild and ultramild SE adhesives (SEAs) $(20,21)$. Since enamel is a mineral composed of compact aggregates of hydroxyapatite crystallites (22), the influence of enamel prism orientation should be considered when an enamel bonding is performed (23). However, since the combination of PA etching and the SE system is different from the conventional etch-and-rinse (ER) system, the enamel bonding strategy must be carefully 
considered. Therefore, the aim of this article is to summarize the current knowledge of reliable enamel bonding in CR restoration via a review of the literature.

\section{ADHESIVE SYSTEMS}

\section{Phosphoric Acid Etching Technique}

A schematic outline of current adhesive systems is presented in Figure 1. The first report of effectively and durably bonding to enamel is an "acid-etch technique" from the study by Buonocore in 1955 (15). In this technique, bonding to enamel requires the PA etching step followed by the application of a fluid resin without the need for an intermediary primer step $(15,24)$. Afterward, Fusayama advocated a "total etch technique" to remove the smear layer (25). In this technique, both the enamel and dentin are etched with PA prior to the application of a bonding agent $(25,26)$. The mechanism of bonding to enamel is thought to be primarily based on micromechanical interlocking of resin into etch pits that are best produced with PA $(27,28)$ as the extent and depth of the etching pattern significantly affects the bond strength to enamel (28-30). Moreover, PA etching modifies the enamel surface topography, substantially increasing its surface energy to the direct benefit of enhancing its wettability (31).

\section{Etch-and-Rinse Strategy}

Following the development of a primer for the conditioning of the dentin, the bonding procedure was revised to the following three primary steps: etching, priming, and bonding. Therefore, this adhesive system is referred to as a 3-step ER system. Subsequently, a simplified 2-step ER system was developed, where the priming and bonding steps are combined to the priming adhesive. However, ER step is still separated from the priming and bonding. Etching with PA requires rinsing with water, unlike the SE system described later. After rinsing with water, the dentin surface should be kept moderately wet (blot dry). Then, the priming adhesive is applied (32). Various studies of collagen-fibril collapse due to post-etching drying recommend keeping the dentin surface visibly moist via the so-called "wet bonding technique" (21). However, the greatest disadvantage of the wet-bonding technique is its high sensitivity to the correctly required degree of dentin-surface wetness, with both overwetting and over-drying dentin severely reducing the adhesive performance $(21,32-34)$. Hence, a systematic review of cervical restorations concluded that the bonding efficiency of 3-step ER is favorable; however, a less favorable bonding performance was noted for 2-step ER (35). In any case, these ER systems require etching with PA because the primer and adhesive have no etching capability, unlike the materials used in the SE strategy described below. However, etching with PA dissolves nearly all of the hydroxyapatite aggregates from the dentin surface at a depth of up to a few micrometers (36). Removing hydroxyapatite as the inorganic dentin component leaves only the organic collagen, which is much more challenging to penetration and diffusion of

Abbreviations: ABRZ, acid-base resistant zone; CR, composite resin; ER, etch-and-rinse; PA, phosphoric acid; SE, self-etch; SEA, self-etch adhesive; 1SEA, 1-step self-etch adhesive; 2-SEA, 2-step self-etch adhesive; SEM, scanning electron microscopy. the monomer (37). Therefore, porous regions of the hybrid layer were more detected in ER adhesives than SEAs, even if there is an absence of gap formation (38). Moreover, in vitro research concluded that a 3-step ER adhesive showed greater deterioration of the bond to dentin compared with a SEA (39). For clinical researches, a systematic review reported that CR restorations in non-carious cervical lesions resulted in similar retention rates and post-operative sensitivity between 3 -step ER adhesives and SEAs (40). However, there is a concern that increased PA etching time resulted in a higher risk of retention failure in Class V CR restorations (41).

\section{Self-Etch Strategy}

In SE strategy, it no longer needs the PA etching step and the water rinsing step, unlike ER strategy. Therefore, the clinical application time became shorter and the technique sensitivity was reduced $(42,43)$. It was achieved by the SE primer that contained the acidic functional monomer and water. In general, the functional monomer contains a carboxyl or phosphate group, which decalcifies the tooth substrate instead of the PA etching. Simultaneously, monomers permeate and diffuse into the dentin during the decalcification process, so that the decalcified dentin collagen fibers are less exposed than with the use of ER adhesive. Moreover, the functional monomers chemically interact with the hydroxyapatite of the tooth substrate, which strengthens and stabilizes the bond to mineralized tooth tissue $(44,45)$. However, not all functional monomers chemically react with hydroxyapatite, such as 10 methacryloxydecyl dihydrogen phosphate which has a chemical bonding potential to calcium of hydroxyapatite (44). The etching effect in SE strategy is ascribed to the acidic functional monomer. Depending on the etching aggressiveness, they can be classified into strong $(\mathrm{pH}<1)$, intermediate $(\mathrm{pH} \approx 1.5)$, mild $(\mathrm{pH} \approx$ $2)$, and ultramild $(\mathrm{pH}>2.5)$ SEAs $(21,42,46,47)$. Strong SEAs present rather deep demineralization effects at both the enamel and the dentin. For enamel, the acid-etch pattern which resembles a PA etching were created (30). This augmentation in the enamel surface area may contribute to micromechanical retention with resin. However, it differs from the PA etching since the dissolved calcium phosphates are not rinsed away. Hence, it is concerned that these embedded calcium phosphates are expected to be very unstable, thereby seriously weakening the interfacial integrity (42). Moreover, strong SEAs demineralized the dentin completely, and expose a hydroxyapatite-depleted collagen network that resembles the one exposed by the total etch approach. Consequently, it showed low bond strength values at dentin (48, 49). Mild SEAs demineralize dentin partially to keep residual hydroxyapatite still attached to collagen (24). Since the demineralization capability of ultramild SEA is limited, the surface preparation method significantly affects the enamel bonding performance. In particular, adhesion to unprepared enamel appeared most challenging (50).

\section{2-Step Self-Etch Adhesives (2-SEAs)}

The characteristic of this system is the SE primer, which combines the etching and priming steps. In this system, the SE primer is applied to the tooth first. Air blowing is then performed, and 


\section{\begin{tabular}{|c|c|}
\hline Acid etch technique & Total etch technique \\
\hline Phosphoric acid etch & Phosphoric acid etch \\
\hline Bixed acrylic resin & Bonding agent \\
\hline Buonocore in 1955 & Fusayama in 1979 \\
\hline
\end{tabular}}
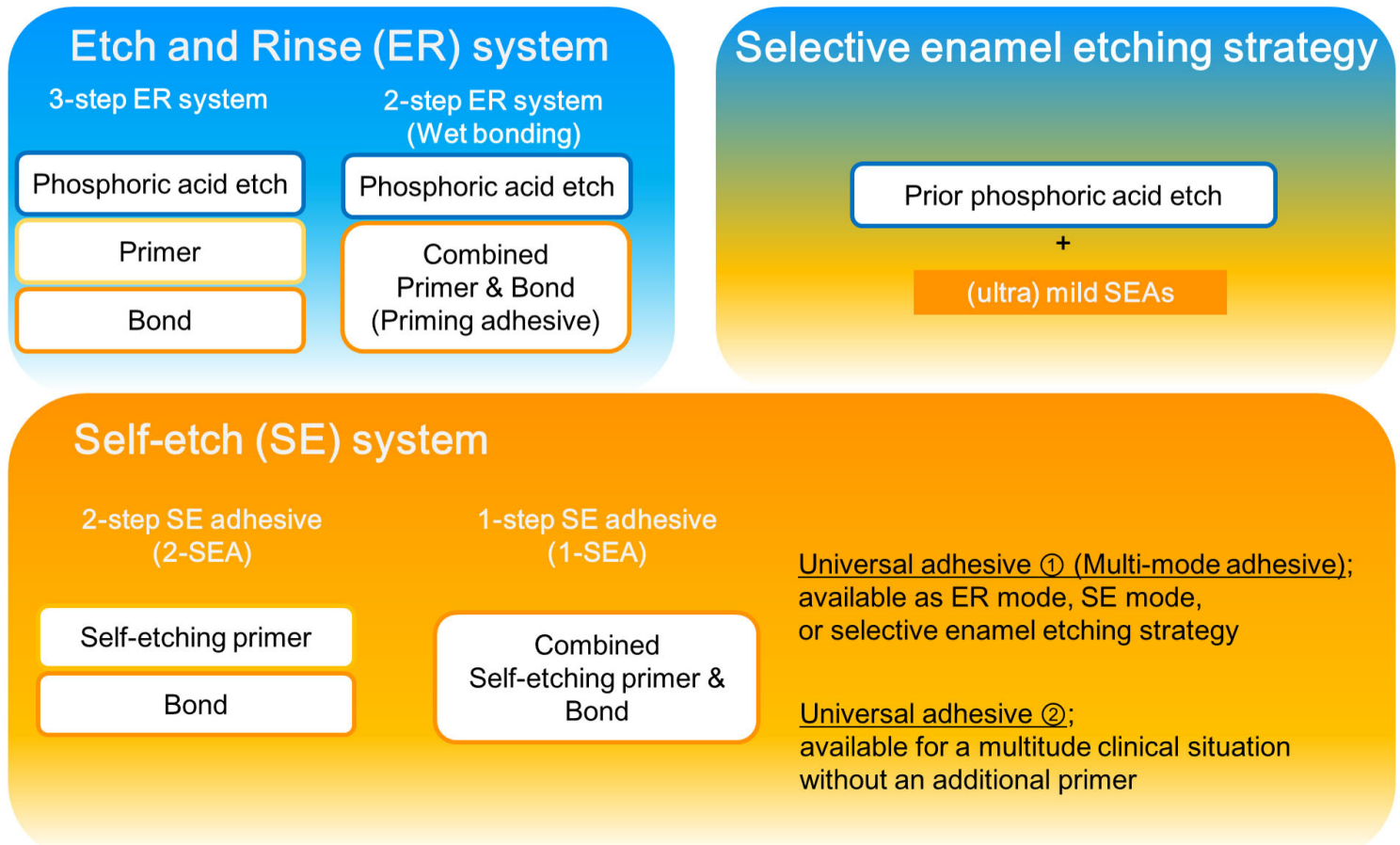

FIGURE 1 | The schematic outline of adhesive systems.

adhesive resin is applied to the tooth. The advantage of 2-SEA is that their efficacy appears to be less dependent on the hydration state of the dentin rather than the ER adhesives (47).

\section{1-Step Self-Etch Adhesives (1-SEAs)}

With the use of a 1-SEA, the etching, priming, and bonding steps are combined in a single application. The 1-SEAs contain hydrophobic monomers, hydrophilic monomers, water, and solvents in one bottle. Furthermore, since 1-SEAs are intricate mixtures of hydrophilic and hydrophobic compounds and water, solvents, such as ethanol or acetone must be contained to maintain miscibility $(51,52)$. However, the evaporation of solvents and water is essential because remnants negatively affect the polymerization of adhesives (53-57). However, the complete evaporation of solvents and water is clinically difficult (58). Therefore, the degree of polymerization of 1-SEAs is generally inferior to that of 2-SEAs.

\section{Universal/Multi-Mode Adhesives}

A new generation of one-bottle dental adhesives is currently available. The 1-SEAs are the most simple-to-use adhesives.
However, the differences in professional judgment regarding the selection of the adhesive strategy and the number of steps still exist. Therefore, more versatile one-bottle dental adhesives which are available as ER mode (with prior PA etching) or SE mode (single-use) adhesives (21) have been released. With the use of this adhesive, clinicians can choose one of the three strategies (ER, SE, or selective enamel etching), depending on the clinical application, rendering the clinical procedure more user-friendly (59). These new dental adhesives are known as "universal" or "multi-mode" adhesives.

Meanwhile, "universal" also means the diversity of clinical applications. Some adhesives are referred to as "universal adhesive" because of the wide range of clinical applications, as silanes for ceramics and indirect composites and adhesive primers for metal alloys and zirconia oxide (59-63). Hence, another characteristic of "universal adhesives" is that they are recommended for a multitude of clinical situations, not only in direct restorations but also in indirect restorations, resin coating, core buildups, zirconia primer, and tooth desensitizer (64). Hence, we have to be careful about interpreting "universal adhesive," as there are two meanings. 


\section{BOND STRENGTH}

Many kinds of laboratory tests have been performed to gather data in the prediction of the eventual clinical outcome. The bond strength test is relatively easy and fast. It, therefore, remains one of the most popular tests in the laboratory. However, there is an excessive number of bond strength data published in the literature, and the variability among the studies is huge. Especially, the difference among the different test set-ups is remarkable (65). To compare the effects of bonding strategies, test methodologies should be standardized. A series of studies $(24,49,66)$ on the application of commercial and experimental adhesives to bur-cut enamel with the same experimental protocol was reported. In the studies, the enamel bond strength of 2SEAs was found to be significantly lower than that of ER adhesives, with the exception of some adhesives, such as the Clearfil SE bond. Further, the bond strength of 1-SEAs was significantly lower than that of ER adhesives and 2-SEAs (24, $49,66)$. Therefore, the studies concluded that the bond strength of ER adhesives to enamel is significantly higher than that of 2SEAs and 1-SEAs (24). These results may be due to insufficient microretention for resin tag formation because (especially mild and ultramild) SEAs have an unsatisfactory (self-) etching effect on the enamel as compared to PA. To compensate for this disadvantage, the application of PA prior to universal adhesives is reported to increase the bond strength to enamel (6769). Moreover, systematic reviews recommend selective enamel etching mode with the use of universal adhesives $(20,70)$.

The outer surface of intact enamel is known to have indistinct and abnormal prism structures, or no prism structures (71). This prismless enamel structure tended to have a stronger resistance to acid than a prismatic enamel surface (72). Therefore, the bond strength test to uncut enamel reported that mild and ultramild SEAs resulted in lower values in the SE mode, and prior PA etching significantly improved the bond strength (73). Thus, micro-mechanical retention of (ultra) mild SEAs for uncut enamel may be weak due to lower etching ability which could not demineralize the prismless layer effectively. Hence, PA etching before the application of (ultra) mild SEAs to an uncut enamel surface is essential to enhance the enamel bond effectiveness (73).

Meanwhile, the strong acidity of PA can weaken the surface structure of enamel. Shimada et al. (23) demonstrated significant interactions between the adhesive system and the direction of enamel rods and found that the bond strength of an ER adhesive was lower with parallel prismatic enamel than vertically sectioned enamel. Moreover, observations of the surface enamel structures using scanning electron microscopy (SEM) showed that etching of the parallel prismatic zone with $35 \%$ PA separated the apatite crystals and subsurface enamel prisms from the deeper part of the enamel (Figure 2). They concluded that the use of PA can "over etch" the parallel prismatic enamel surface, resulting in weaker bonding (23).

A number of acid-etching protocols were used for enamel adhesion. A systematic review showed that PAs at concentrations between 30 and $40 \%$ were most commonly tested clinically (74). When different concentrations of PA were used in vitro, concentrations lower than $30 \%$ were concluded to be insufficient in producing enough enamel dissolution for bonding (75). While PA concentrations higher than $50 \%$ presented fewer surface morphologic changes (76), this review paper also mentioned that an etching time of 15 or $30 \mathrm{~s}$ has become the prevailing method of PA etching in recent years with the clinical advantages (74). On the one hand, increasing PA pre-etching time from 15 to $60 \mathrm{~s}$ produced greater surface roughness, but did not improve the enamel bond strength of SEAs (77). On the other hand, the reduced PA etching time did not influence the bond strength and surface area, although the surface roughness decreased with decreasing etching time (78). Spending less time on PA etching can save chairside time, decrease the chance of surface contamination, minimize the subsurface substance dissolution, and be more biocompatible when enamel and dentin are etched at the same time (74). From these studies, pre-etching times of below $15 \mathrm{~s}$ can sufficiently improve the bond strength of (ultra) mild SEAs.

\section{BONDING INTERFACE}

\section{Leakage Test}

Good mechanical retention and chemical bonding are both important to obtain reliable bonding, as determined by bond strength testing as well as morphological studies. In particular, SEM of the bond interface has revealed useful information to better understand the bonding mechanisms of adhesives to tooth substrates (45). The longevity of an adhesive composite restoration is mainly compromised by the leakage of oral fluids along the interface between the restorative material and tooth substrate $(79,80)$. Hence, the sealing ability should be evaluated to predict the clinical performance of adhesives with regard to the occurrence of post-operative sensitivity and/or secondary caries (80). For in vitro evaluation of sealing ability, leakage tests are preferred over other methods, such as SEM, for the evaluation of marginal adaptation/gap formation, bacterial leakage, and permeability assessments, which are more laborious, time-consuming, or technique-sensitive (81). However, this cross section based procedure allows only a limited 2D-view on the distribution of the marker fluid, by which it is for instance not possible to determine the point of deepest leakage with certainty (65). Microleakage is assessed in vitro microscopically on cross sections using a wide variety of tracers or dyes. Hence, the reliability of microleakage protocols remains controversial due to the variability of methodology employed worldwide $(79,82,83)$. Nanoleakage is assessed using Ag-ions that are extremely small $(0.059 \mathrm{~nm})$. This nanoleakage refers to leakage within nanometer-sized channels along the adhesive interface, even in the absence of a marginal gap (38). These voids are so small that bacteria may not be able to pass through, but these spaces may be more susceptible to degradation. Optimal enamel bonding is primarily based on micromechanical interlocking of a low-viscosity resin into microporosities. Hence, nanoleakage in the enamel bonding interface may be caused by insufficient infiltration of the resin into the demineralized enamel or incomplete polymerization of monomers in the nanometersized interfacial space. In addition, the extent and depth of the 
A

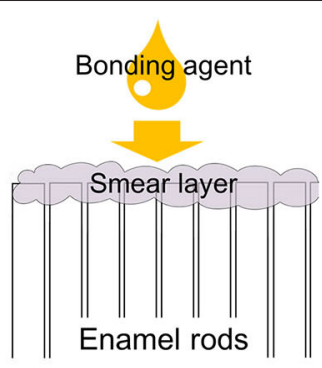

B
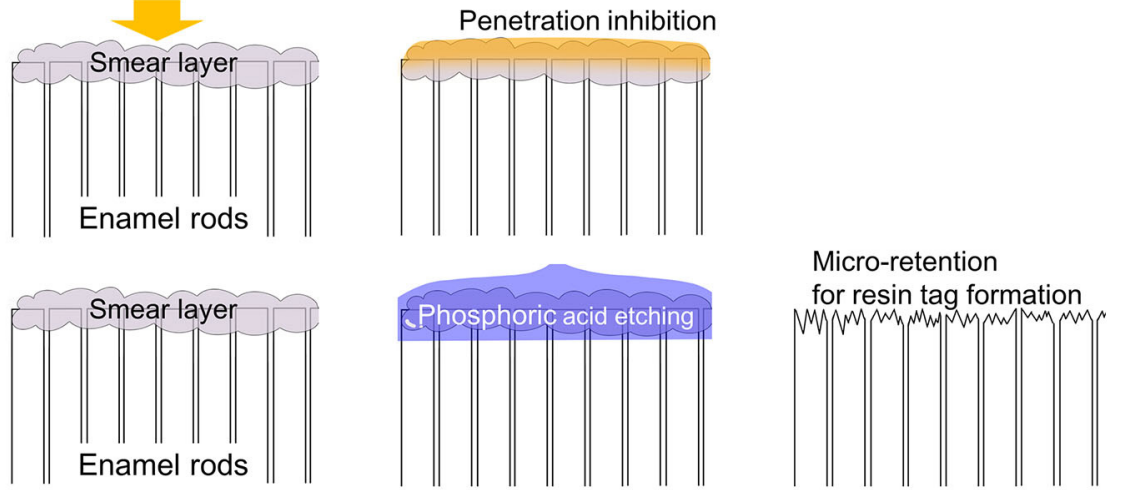

C
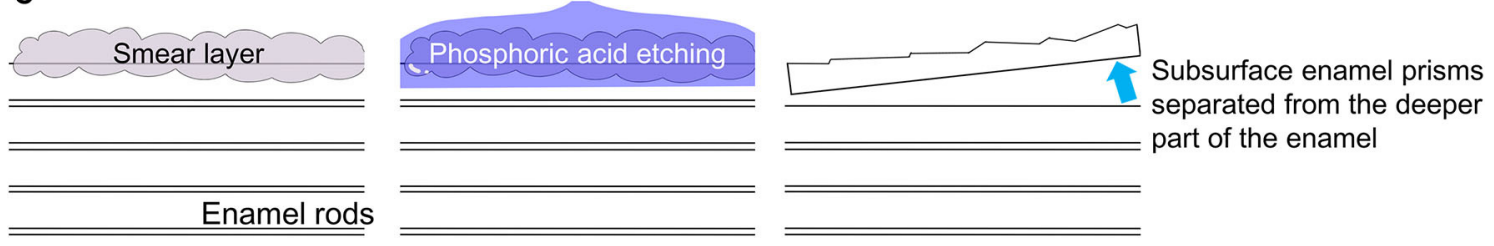

FIGURE 2 | Effects of regional enamel and prism orientation. (A) For monomer penetration, the smear layer should be removed by etching. (B) A horizontally sectioned enamel surface is roughened by PA etching. (C) Unsupported apatite crystals were observed on the surface of axially sectioned enamel after PA etching.

etching pattern can influence the mechanical behavior of the adhesive (84). Importantly, some studies reported the absence of any correlation between nanoleakage and the bond strength of adhesives (85-88).

The application of PA roughens and increases the porosity of the enamel surface, which improves the bonding potential of SEAs, resulting in an initially superior marginal seal (89). Previous microleakage studies have reported that etching with PA prior to the application of 1-SEAs reduces microleakage at the enamel bonding interface $(90,91)$. For 2-SEAs, microleakage studies reported that there was no difference in the extent of leakage with the use of a 2-SEA regardless of etching with PA $(81,90)$. For nanoleakage studies, Perdigão et al. (92) reported significantly less leakage with the use of a 2-SEA (Clearfil SE Bond, pH 1.8, Kuraray America, Houston, TX, USA) than 1-SEAs (Adper Prompt L-Pop, pH 0.9, 3M ESPE, Seefeld, Germany; iBond, pH 2.2, Heraeus Kulzer, Hanau, Germany). Additionally, PA etching reportedly improved the sealing ability of iBond but not that of others (92). Another study using 1-SEAs showed that nanoleakage is material-dependent, irrespective of preliminary PA etching (93). These studies suggest that not only the adhesive system but also the $\mathrm{pH}$ value of the adhesive influences the sealing ability at the enamel bonding interface. Moreover, nanoleakage was detected in 2-SEAs with PA although not detected in 2-SEAs without PA (94). This study suggested that deep jaggedness created by PA etching on the enamel surface renders a challenge to water and solvent evaporations (94). Therefore, these residual hydrophilic solvents might compete with the hydrophobic monomers that are contained in adhesive resin, for example, Bis-GMA, which triggers a nanoleakage. Halabi et al. (95) reported that nanoleakage was observed in the interface between 1-SEAs and the enamel, while not observed in between 1-SEAs and the bleached enamel (95). They noted that a bleaching agent will denature enamel proteins, which may create macrospaces for more effective penetration of the adhesive monomers into the enamel. Monticelli et al. (89) concluded that ER adhesives offer the most predictable bonding to enamel, although the adhesive potential of 2-SEAs was significantly reduced when bonded to dentin etched by PA. Hence, PA etching of dentin prior to the application of a SEA should be avoided. To seal the enamel bonding interface, selective enamel etching is recommended when using (ultra) mild SEAs.

\section{Acid-Base Resistant Zone}

Scanning electron microscopy examinations of the bonding interface after acid and base challenges have yielded useful information to assess the resistance to secondary caries. Tsuchiya et al. (96) reported an acid-base resistant zone (ABRZ) beneath the hybrid layer of a SEA-dentin interface after an acid than base challenge. A later study by Li et al. (97) detected the enamel, ABRZ. These studies reported that an ABRZ remained after an acid challenge, although the tooth substrate (i.e., enamel or dentin) was dissolved by an artificial demineralization solution (Figure 3). Therefore, ABRZ is believed to play an important role in inhibiting damage from recurrent caries by sealing restoration margins, which can then promote restoration durability by maintaining the bond (98). However, ABRZ 


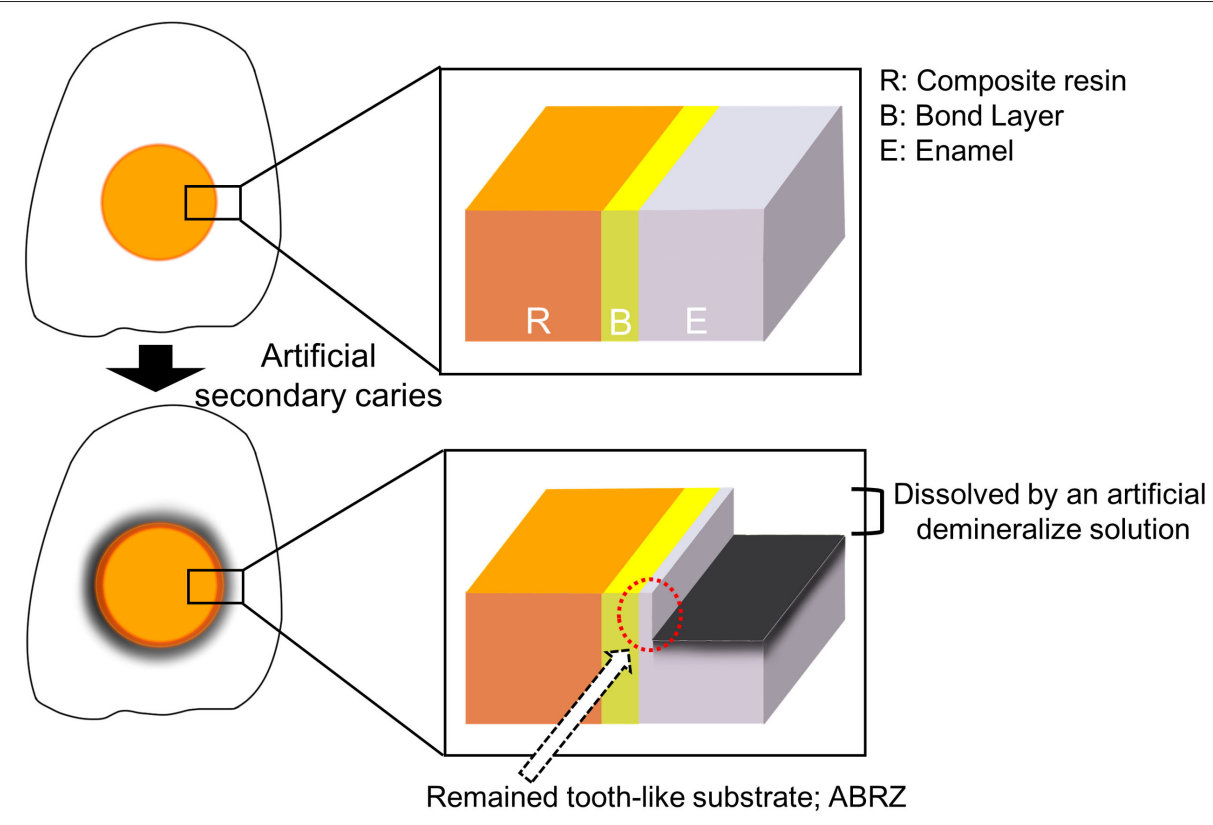

FIGURE 3 | The schematic design of an ABRZ. An ABRZ is observed beneath the bonding interface as a tooth-like substrate despite an artificial demineralize solution dissolves the enamel substrate.

formation is reportedly dependent on the adhesive material (45, 99). Li et al. (97) observed an ABRZ of the enamel following the application of 2-SEAs containing the functional monomer 10methacryloxydecyl dihydrogen phosphate but not with 2-SEAs containing the functional monomer phenyl-P. Subsequently, the ABRZ of the enamel was also observed following the application of 1-SEAs or universal adhesives containing 10methacryloxydecyl dihydrogen phosphate $(100,101)$. However, the funnel-shaped erosion beneath the enamel bonding interface was detected following the application of 1-SEAs or universal adhesives, but not of 2-SEAs $(100,101)$. This type of erosion indicates that the enamel substrate beneath the bonding interface of 1-SEAs or universal adhesives is more easily dissolved than the intact enamel. The results of these studies raise doubts regarding the acid-resistance ability of 1-SEAs and universal adhesives as SE mode on enamel even if an ABRZ forms on the enamel. Meanwhile, etching with PA prior to the application of SEAs (i.e., 2-SEAs, 1-SEAs, and universal adhesives) promotes the thickness of the ABRZ of the enamel (100-102). Additionally, etching with PA prior to the application of 1-SEAs or universal adhesives (i.e., selective enamel etching mode) prevented the formation of the funnel-shaped erosions on the enamel bonding interface (100, 101). These morphological studies suggest that prior etching with $\mathrm{PA}$ is essential to create a stable enamel bonding interface for the use of 1-SEAs and universal adhesives, but it is not essential for the use of 2-SEAs (Figure 4).

\section{CLINICAL RESEARCH}

Clinical trials are the ultimate test for dental restorations (24); however, all sorts of chemical and mechanical challenges that are inherent to the oral environment should be taken into account (103). Hence, clinical assessments have been often performed using Class-V lesions or non-carious cervical lesions (NCCLs), because these cavities do not provide any macro-mechanical retention and have a relatively small C-factor (65). The systematic review revealed that both 1 -SEAs and 2-SEAs have comparable clinical effectiveness; however, there was a statistical difference in relation to marginal adaptation (104). Another systematic review concluded that selective enamel etching prior to application of SEAs might improve the clinical performance of CR restorations in NCCLs (105). For mild 2-SEAs, clinical trials reported that SE strategy showed clinically acceptable small marginal defect and/or superficial marginal discoloration compared to selective enamel etching; however, the difference was not statistically significant $(5,6)$. For universal adhesives, in contrast, without PA etching showed that marginal discoloration (13) and small marginal fractures (10) were significantly worse. These defects can be explained by the theory of the funnel-shaped erosion formation on ABRZ studies (100, 101) (Figure 4).

\section{DISCUSSION}

\section{Alternative Approaches to the PA Application}

Although PA etching definitely improves bonding of 1-SEAs and universal adhesives to enamel, the bonding interface of dentin becomes vulnerable in ER strategy (67). Hence, the ideal strategy when using 1-SEAs and universal adhesives is to etch the enamel and dentin separately. However, strict selective etching of the enamel may be clinically difficult. Thus, various novel 


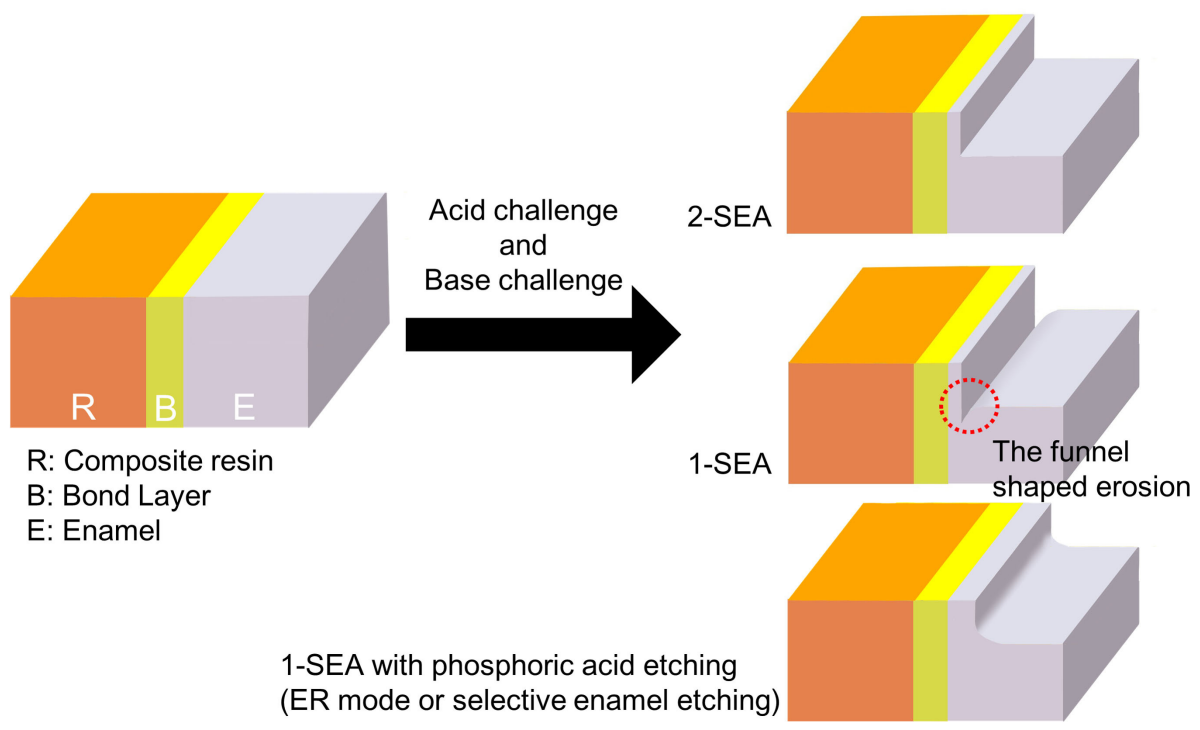

FIGURE 4 | Morphological differences in enamel ABRZ. The funnel-shaped erosion was detected beneath the bonding interface with 1-SEAs. The formation of this erosion can be prevented by prior PA etching.

approaches have been investigated in vitro. For example, doublelayer application of universal adhesives was reported to increase the enamel bond strength $(106,107)$, but not effective for 2-SEA (106). The active application of universal adhesives in the SE mode may be an alternative to increase the adhesive properties in the enamel $(108,109)$. However, the active application of universal adhesives in the ER mode exhibited significantly lower bonding strength (110). Another approach is to apply the alternative etching agent which has milder acidity than PA to prevent degradation of the dentin. Since SEAs have etching capabilities themselves, unlike 3-step ER system, the use of an etchant with milder acidity to PA might be adequate. Some in vitro studies demonstrated that an alternative etchant applied prior to a universal adhesive improved the enamel bonding performance (111-114). Moreover, unlike PA, this etchant had no bad effect on the dentin bonding performance (115). On the basis of the findings of these studies, this etchant might be suitable for simultaneous application to both the enamel and dentin to elicit the high performance of a universal adhesive. However, little information is available about the application to uncut enamel or the clinical outcome. Hence, further researches are warranted.

\section{Conclusion}

The latest adhesive system, a universal adhesive, can simplify the treatment procedure and reduce the chair time but not necessarily optimize the tooth bonding strategy. From the

\section{REFERENCES}

1. Türkün SL. Clinical evaluation of a self-etching and a onebottle adhesive system at two years. J Dent. (2003) 31:52734. doi: 10.1016/s0300-5712(03)00107-6 current literature of enamel bonding, selective enamel etching is recommended prior to the application of (ultra) mild SEAs. When using PA with SEAs, it is recommended that the concentration of $\mathrm{PA}$ is between 30 and $50 \%$, etching time is under $15 \mathrm{~s}$; if not, it is advisable to not perform the active application. SEAs result in adequate CR restoration outcomes, and prior etching improves the quality of the enamel margin.

\section{AUTHOR CONTRIBUTIONS}

TS contributed to the conception, designing, drafting, and drawing of the figures as well as the critical revision of the manuscript. TT and JT contributed to the conception, designing, and critical revision of the manuscript. $\mathrm{TH}$ contributed to the conception, design, and drawing of the figures as well as the critical revision of the manuscript. TN contributed to the conception, designing, interpretation, and critical revision of the manuscript. All authors gave final approval and agreed to be accountable for all aspects of the work.

\section{FUNDING}

This work was supported by JSPS KAKENHI Grant Numbers JP17K17119 and JP20K18524. 
3. Barcellos DC, Batista GR, Silva MA, Pleffken PR, Rangel PM, Fernandes $\mathrm{VV}$ Jr, et al. Two-year clinical performance of self-etching adhesive systems in composite restorations of anterior teeth. Oper Dent. (2013) 38:25866. doi: 10.2341/11-397-C

4. Farias DC, Lopes GC, Baratieri LN. Two-year clinical performance of a twostep etch-and-rinse adhesive in non-carious cervical lesions: influence of subject's age and dentin etching time. Clin Oral Investig. (2015) 19:186774. doi: 10.1007/s00784-015-1399-2

5. Peumans M, De Munck J, Van Landuyt K, Van Meerbeek B. Thirteen-year randomized controlled clinical trial of a two-step selfetch adhesive in non-carious cervical lesions. Dent Mater. (2015) 31:308-14. doi: 10.1016/j.dental.2015.01.005

6. Pena CE, Rodrigues JA, Ely C, Giannini M, Reis AF. Two-year randomized clinical trial of self-etching adhesives and selective enamel etching. Oper Dent. (2016) 41:249-57. doi: 10.2341/15-130-C

7. Burke FJT, Crisp RJ, Cowan AJ, Raybould L, Redfearn P, Sands P, et al. A randomised controlled trial of a universal bonding agent at three years: self etch vs total etch. Eur J Prosthodont Restor Dent. (2017) 25:2207. doi: 10.1922/EJPRD_01692Burke08

8. Peumans M, Wouters L, De Munck J, Van Meerbeek B, Van Landuyt K. Nine-year clinical performance of a HEMA-free one-step self-etch adhesive in noncarious cervical lesions. J Adhes Dent. (2018) 20:195203. doi: 10.3290/j.jad.a40630

9. Dutra-Correa M, Kiyan VH, Ciaramicoli MT, Pecorari V, Rodrigues FP, Coury Saraceni CH. Randomized clinical trial of four adhesion strategies: a 42 month study. Indian J Dent Res. (2019) 30:48795. doi: 10.4103/ijdr.IJDR_466_16

10. Haak R, Hähnel M, Schneider H, Rosolowski M, Park KJ, Ziebolz $\mathrm{D}$, et al. Clinical and OCT outcomes of a universal adhesive in a randomized clinical trial after 12 months. J Dent. (2019) 90:103200. doi: 10.1016/j.jdent.2019.103200

11. Ruschel VC, Stolf SC, Shibata S, Chung Y, Boushell LW, Baratieri LN, et al. Three-year clinical evaluation of universal adhesives in non-carious cervical lesions. Am J Dent. (2019) 32:223-8.

12. de Paris Matos T, Perdigão J, de Paula E, Coppla F, Hass V, Scheffer RF, et al. Five-year clinical evaluation of a universal adhesive: a randomized doubleblind trial. Dent Mater. (2020) 36:1474-85. doi: 10.1016/j.dental.2020.08.007

13. Rouse MA, May JT, Platt JA, Cook NB, Capin OR, Adams BN, et al. Clinical evaluation of a universal adhesive in non-carious cervical lesions. $J$ Esthet Restor Dent. (2020) 32:691-8. doi: 10.1111/jerd.12622

14. Sato T, Matsuyama Y, Fujiwara T, Tagami J. Pulp survival after composite resin restoration of caries lesions in adults. J Oral Sci. (2020) 63:2730. doi: 10.2334/josnusd.19-0534

15. Buonocore MG. A simple method of increasing the adhesion of acrylic filling materials to enamel surfaces. J Dent Res. (1955) 34:84953. doi: $10.1177 / 00220345550340060801$

16. Burrow MF, Tagami J, Hosoda $\mathrm{H}$. The long term durability of bond strengths to dentin. Bull Tokyo Med Dent Univ. (1993) 40:173-91.

17. Sano H, Shono T, Takatsu T, Hosoda H. Microporous dentin zone beneath resin-impregnated layer. Oper Dent. (1994) 19:59-64.

18. Pashley DH, Tay FR, Yiu C, Hashimoto M, Breschi L, Carvalho RM, et al. Collagen degradation by host-derived enzymes during aging. J Dent Res. (2004) 83:216-21. doi: 10.1177/154405910408300306

19. De Munck J, Van den Steen PE, Mine A, Van Landuyt KL, Poitevin A, Opdenakker G, et al. Inhibition of enzymatic degradation of adhesive-dentin interfaces. J Dent Res. (2009) 88:1101-6. doi: 10.1177/0022034509346952

20. Rosa WL, Piva E, Silva AF. Bond strength of universal adhesives: a systematic review and meta-analysis. J Dent. (2015) 43:765-76. doi: 10.1016/j.jdent.2015.04.003

21. Van Meerbeek B, Yoshihara K, Van Landuyt K, Yoshida Y, Peumans M. From Buonocore's Pioneering acid-etch technique to self-adhering restoratives. A status perspective of rapidly advancing dental adhesive technology. J Adhes Dent. (2020) 22:7-34. doi: 10.3290/j.jad.a43994

22. Teruel J de D, Alcolea A, Hernández A, Ruiz AJ. Comparison of chemical composition of enamel and dentine in human, bovine, porcine and ovine teeth. Arch Oral Biol. (2015) 60:768-75. doi: 10.1016/j.archoralbio.2015.01.014
23. Shimada Y, Tagami J. Effects of regional enamel and prism orientation on resin bonding. Oper Dent. (2003) 28:20-7.

24. Van Meerbeek B, De Munck J, Yoshida Y, Inoue S, Vargas M, Vijay P, et al. Buonocore memorial lecture. Adhesion to enamel and dentin: current status and future challenges. Oper Dent. (2003) 28:215-35.

25. Fusayama T, Nakamura M, Kurosaki N, Iwaku M. Non-pressure adhesion of a new adhesive restorative resin. J Dent Res. (1979) 58:136470. doi: 10.1177/00220345790580041101

26. Fusayama T. Total etch technique and cavity isolation. J Esthet Dent. (1992) 4:105-9. doi: 10.1111/j.1708-8240.1992.tb00674.x

27. Buonocore MG, Matsui A, Gwinnett AJ. Penetration of resin dental materials into enamel surfaces with reference to bonding. Arch Oral Biol. (1968) 13:61-70. doi: 10.1016/0003-9969(68)90037-x

28. Hannig $M$, Bock $H$, Bott $B$, Hoth-Hannig W. Inter-crystallite nanoretention of self-etching adhesives at enamel imaged by transmission electron microscopy. Eur J Oral Sci. (2002) 110:464-70. doi: 10.1034/j.1600-0722.2002.21326.x

29. Perdigão J, Lopes L, Lambrechts P, Leitão J, Van Meerbeek B, Vanherle G. Effects of a self-etching primer on enamel shear bond strengths and SEM morphology. Am J Dent. (1997) 10:141-6.

30. Pashley DH, Tay FR. Aggressiveness of contemporary self-etching adhesives. Part II: etching effects on unground enamel. Dent Mater. (2001) 17:43044. doi: 10.1016/s0109-5641(00)00104-4

31. Tsujimoto A, Shimatani Y, Nojiri K, Barkmeier WW, Markham MD, Takamizawa T, et al. Influence of surface wetness on bonding effectiveness of universal adhesives in etch-and-rinse mode. Eur J Oral Sci. (2019) 127:1629. doi: 10.1111/eos.12596

32. Tay FR, Gwinnett AJ, Pang KM, Wei SH. Resin permeation into acidconditioned, moist, and dry dentin: a paradigm using water-free adhesive primers. J Dent Res. (1996) 75:1034-44. doi: 10.1177/00220345960750040601

33. Pereira GD, Paulillo LA, De Goes MF, Dias CT. How wet should dentin be? Comparison of methods to remove excess water during moist bonding. $J$ Adhes Dent. (2001) 3:257-64.

34. Tay FR, Gwinnett JA, Wei SH. Micromorphological spectrum from overdrying to overwetting acid-conditioned dentin in water-free acetone-based, single-bottle primer/adhesives. Dent Mater. (1996) 12:236-44. doi: 10.1016/s0109-5641(96)80029-7

35. Peumans M, De Munck J, Mine A, Van Meerbeek B. Clinical effectiveness of contemporary adhesives for the restoration of noncarious cervical lesions. A systematic review. Dent Mater. (2014) 30:1089-103. doi: 10.1016/j.dental.2014.07.007

36. Pashley DH, Tay FR, Breschi L, Tjäderhane L, Carvalho RM, Carrilho M, e al. State of the art etch-and-rinse adhesives. Dent Mater. (2011) 27:116. doi: 10.1016/j.dental.2010.10.016

37. Van Meerbeek B, De Munck J, Mattar D, Van Landuyt K, Lambrechts P. Microtensile bond strengths of an etch\&rinse and self-etch adhesive to enamel and dentin as a function of surface treatment. Oper Dent. (2003) 28:647-60.

38. Sano H, Takatsu T, Ciucchi B, Horner JA, Matthews WG, Pashley DH. Nanoleakage: leakage within the hybrid layer. Oper Dent. (1995) 20:18-25.

39. Burrow MF, Harada N, Kitasako Y, Nikaido T, Tagami J. Seven-year dentin bond strengths of a total- and self-etch system. Eur J Oral Sci. (2005) 113:265-70. doi: 10.1111/j.1600-0722.2005.00213.x

40. Schroeder M, Correa IC, Bauer J, Loguercio AD, Reis A. Influence of adhesive strategy on clinical parameters in cervical restorations: a systematic review and meta-analysis. J Dent. (2017) 62:36-53. doi: 10.1016/j.jdent.2017.05.006

41. Rocha AC, Salas MS, Masotti AS, da Rosa W, Zanchi CH, Lund RG. A randomized double-blind clinical trial of dentin surface treatments for composite restorations in noncarious cervical lesions: a 36-month evaluation. Oper Dent. (2019) 44:114-26. doi: 10.2341/17-308-C

42. Van Meerbeek B, Yoshihara K, Yoshida Y, Mine A, De Munck J, Van Landuyt KL. State of the art of self-etch adhesives. Dent Mater. (2011) 27:17-28. doi: 10.1016/j.dental.2010.10.023

43. Perdigão J, Muñoz MA, Sezinando A, Luque-Martinez IV, Staichak R, Reis A, et al. Immediate adhesive properties to dentin and enamel of a universal adhesive associated with a hydrophobic resin coat. Oper Dent. (2014) 39:48999. doi: 10.2341/13-203-LR 
44. Yoshida Y, Nagakane K, Fukuda R, Nakayama Y, Okazaki M, Shintani H, et al. Comparative study on adhesive performance of functional monomers. $J$ Dent Res. (2004) 83:454-8. doi: 10.1177/154405910408300604

45. Nikaido T, Takagaki T, Sato T, Burrow MF, Tagami J. The concept of super enamel formation-relationship between chemical interaction and enamel acid-base resistant zone at the self-etch adhesive/enamel interface. Dent Mater J. (2020) 39:534-8. doi: 10.4012/dmj.2020-165

46. De Munck J, Vargas M, Iracki J, Van Landuyt K, Poitevin A, Lambrechts P, et al. One-day bonding effectiveness of new self-etch adhesives to bur-cut enamel and dentin. Oper Dent. (2005) 30:39-49.

47. Sofan E, Sofan A, Palaia G, Tenore G, Romeo U, Migliau G. Classification review of dental adhesive systems: from the IV generation to the universal type. Ann Stomatol (Roma). (2017) 8:1-17. doi: 10.11138/ads/2017.8.1.001

48. Inoue S, Vargas MA, Abe Y, Yoshida Y, Lambrechts P, Vanherle G, et al. Microtensile bond strength of eleven contemporary adhesives to dentin. $J$ Adhes Dent. (2001) 3:237-45.

49. De Munck J, Van Meerbeek B, Satoshi I, Vargas M, Yoshida Y, Armstrong S, et al. Microtensile bond strengths of one- and two-step self-etch adhesives to bur-cut enamel and dentin. Am J Dent. (2003) 16:414-20.

50. Mine A, De Munck J, Vivan Cardoso M, Van Landuyt KL, Poitevin A, Kuboki T, et al. Enamel-smear compromises bonding by mild self-etch adhesives. $J$ Dent Res. (2010) 89:1505-9. doi: 10.1177/0022034510384871

51. De Munck J, Van Landuyt K, Peumans M, Poitevin A, Lambrechts P, Braem $\mathrm{M}$, et al. A critical review of the durability of adhesion to tooth tissue: methods and results. J Dent Res. (2005) 84:11832. doi: 10.1177/154405910508400204

52. Van Landuyt KL, Peumans M, De Munck J, Lambrechts P, Van Meerbeek B. Extension of a one-step self-etch adhesive into a multi-step adhesive. Dent Mater. (2006) 22:533-44. doi: 10.1016/j.dental.2005.05.010

53. Suh BI, Feng L, Pashley DH, Tay FR. Factors contributing to the incompatibility between simplified-step adhesives and chemically-cured or dual-cured composites. Part III. Effect of acidic resin monomers. J Adhes Dent. (2003) 5:267-82.

54. Frankenberger R, Strobel WO, Lohbauer U, Krämer N, Petschelt A. The effect of six years of water storage on resin composite bonding to human dentin. I Biomed Mater Res B Appl Biomater. (2004) 69:2532. doi: 10.1002/jbm.b.20024

55. Tay FR, Pashley DH, Suh BI, Hiraishi N, Yiu CK. Water treeing in simplified dentin adhesives-déjà vu? Oper Dent. (2005) 30:561-79.

56. Van Landuyt KL, Snauwaert J, De Munck J, Peumans M, Yoshida Y, Poitevin A, et al. Systematic review of the chemical composition of contemporary dental adhesives. Biomaterials. (2007) 28:3757-85. doi: 10.1016/j.biomaterials.2007.04.044

57. Loguercio AD, Loeblein F, Cherobin T, Ogliari F, Piva E, Reis A. Effect of solvent removal on adhesive properties of simplified etch-and-rinse systems and on bond strengths to dry and wet dentin. J Adhes Dent. (2009) 11:213-9.

58. Ikeda $T$, De Munck J, Shirai K, Hikita K, Inoue S, Sano $H$, et al. Effect of evaporation of primer components on ultimate tensile strengths of primer-adhesive mixture. Dent Mater. (2005) 21:10518. doi: 10.1016/j.dental.2005.03.010

59. Perdigão J, Kose C, Mena-Serrano AP, De Paula EA, Tay LY, Reis A, et al. A new universal simplified adhesive: 18-month clinical evaluation. Oper Dent. (2014) 39:113-27. doi: 10.2341/13-045-C

60. Marchesi G, Frassetto A, Mazzoni A, Apolonio F, Diolosà M, Cadenaro M, et al. Adhesive performance of a multi-mode adhesive system: 1-year in vitro study. J Dent. (2014) 42:603-12. doi: 10.1016/j.jdent.2013.12.008

61. Wagner A, Wendler M, Petschelt A, Belli R, Lohbauer U. Bonding performance of universal adhesives in different etching modes. J Dent. (2014) 42:800-7. doi: 10.1016/j.jdent.2014.04.012

62. Kalavacharla VK, Lawson NC, Ramp LC, Burgess JO. Influence of etching protocol and silane treatment with a universal adhesive on lithium disilicate bond strength. Oper Dent. (2015) 40:372-8. doi: 10.2341/14-116-L

63. Kim JH, Chae SY, Lee Y, Han GJ, Cho BH. Effects of multipurpose, universal adhesives on resin bonding to zirconia ceramic. Oper Dent. (2015) 40:5562. doi: 10.2341/13-303-L

64. Perdigão J, Araujo E, Ramos RQ, Gomes G, Pizzolotto L. Adhesive dentistry: current concepts and clinical considerations. J Esthet Restor Dent. (2021) 33:51-68. doi: $10.1111 /$ jerd.12692
65. Van Meerbeek B, Peumans M, Poitevin A, Mine A, Van Ende A, Neves A, et al. Relationship between bond-strength tests and clinical outcomes. Dent Mater. (2010) 26:e100-21. doi: 10.1016/j.dental.2009.11.148

66. Inoue S, Vargas MA, Abe Y, Yoshida Y, Lambrechts P, Vanherle G, et al. Microtensile bond strength of eleven contemporary adhesives to enamel. Am J Dent. (2003) 16:329-34.

67. Hanabusa M, Mine A, Kuboki T, Momoi Y, Van Ende A, Van Meerbeek B, et al. Bonding effectiveness of a new 'multi-mode' adhesive to enamel and dentine. J Dent. (2012) 40:475-84. doi: 10.1016/j.jdent.2012.02.012

68. Pongprueksa P, De Munck J, Barreto BC, Karunratanakul K, Van Meerbeek B. Mini-interfacial fracture toughness as a new validated enamelbonding effectiveness test. J Mech Behav Biomed Mater. (2016) 62:44655. doi: 10.1016/j.jmbbm.2016.05.022

69. Vermelho PM, Reis AF, Ambrosano GMB, Giannini M. Adhesion of multimode adhesives to enamel and dentin after one year of water storage. Clin Oral Investig. (2017) 21:1707-15. doi: 10.1007/s00784-016-1966-1

70. Cuevas-Suárez CE, da Rosa WLO, Lund RG, da Silva AF, Piva E. Bonding performance of universal adhesives: an updated systematic review and metaanalysis. J Adhes Dent. (2019) 21:7-26. doi: 10.3290/j.jad.a41975

71. Kodaka T, Kuroiwa M, Higashi S. Structural and distribution patterns of surface 'prismless' enamel in human permanent teeth. Caries Res. (1991) 25:7-20. doi: 10.1159/000261336

72. Kuroiwa M. Acid resistance of surface 'prismless' enamel in human deciduous and permanent teeth. Showa Univ J Med Sci. (1990) 2:31-44.

73. Takeda M, Takamizawa T, Imai A, Suzuki T, Tsujimoto A, Barkmeier WW, et al. Immediate enamel bond strength of universal adhesives to unground and ground surfaces in different etching modes. Eur J Oral Sci. (2019) 127:351-60. doi: 10.1111/eos.12626

74. Zhu JJ, Tang AT, Matinlinna JP, Hägg U. Acid etching of human enamel in clinical applications: a systematic review. J Prosthet Dent. (2014) 112:12235. doi: 10.1016/j.prosdent.2013.08.024

75. Chow LC, Brown WE. Phosphoric acid conditioning of teeth for pit and fissure sealants. J Dent Res. (1973) 52:1158. doi: 10.1177/00220345730520053501

76. Silverstone LM. Fissure sealants. Laboratory studies. Caries Res. (1974) 8:2-26. doi: 10.1159/000260090

77. Barkmeier WW, Erickson RL, Kimmes NS, Latta MA, Wilwerding TM. Effect of enamel etching time on roughness and bond strength. Oper Dent. (2009) 34:217-22. doi: 10.2341/08-72

78. Tsujimoto A, Fischer N, Barkmeier W, Baruth A, Takamizawa T, Latta M, et al. Effect of reduced phosphoric acid pre-etching times on enamel surface characteristics and shear fatigue strength using universal adhesives. J Adhes Dent. (2017) 19:267-75. doi: 10.3290/j.jad.a38437

79. Raskin A, D’Hoore W, Gonthier S, Degrange M, Déjou J. Reliability of in vitro microleakage tests: a literature review. J Adhes Dent. (2001) 3:295-308.

80. de Almeida JB, Platt JA, Oshida Y, Moore BK, Cochran MA, Eckert GJ. Three different methods to evaluate microleakage of packable composites in Class II restorations. Oper Dent. (2003) 28:453-60.

81. Rengo C, Goracci C, Juloski J, Chieffi N, Giovannetti A, Vichi A, et al. Influence of phosphoric acid etching on microleakage of a self-etch adhesive and a self-adhering composite. Aust Dent J. (2012) 57:2206. doi: 10.1111/j.1834-7819.2012.01689.x

82. Heintze SD. Systematic reviews: I. The correlation between laboratory tests on marginal quality and bond strength. II. The correlation between marginal quality and clinical outcome. J Adhes Dent. (2007) 9:77-106.

83. Amarante de Camargo DA, Sinhoreti MA, Correr-Sobrinho L, de Sousa Neto $\mathrm{MD}$, Consani S. Influence of the methodology and evaluation criteria on determining microleakage in dentin-restorative interfaces. Clin Oral Investig. (2006) 10:317-23. doi: 10.1007/s00784-006-0061-4

84. Van Landuyt KL, Kanumilli P, De Munck J, Peumans M, Lambrechts P, Van Meerbeek B. Bond strength of a mild self-etch adhesive with and without prior acid-etching. J Dent. (2006) 34:77-85. doi: 10.1016/j.jdent.2005.04.001

85. Okuda M, Pereira PN, Nakajima M, Tagami J. Relationship between nanoleakage and long-term durability of dentin bonds. Oper Dent. (2001) 26:482-90.

86. Guzmán-Armstrong S, Armstrong SR, Qian F. Relationship between nanoleakage and microtensile bond strength at the resin-dentin interface. Oper Dent. (2003) 28:60-6. 
87. Hashimoto $\mathrm{M}$, De Munck J, Ito $\mathrm{S}$, Sano $\mathrm{H}$, Kaga $\mathrm{M}$, Oguchi $\mathrm{H}$, et al. In vitro effect of nanoleakage expression on resin-dentin bond strengths analyzed by microtensile bond test, SEM/EDX and TEM. Biomaterials. (2004) 25:556574. doi: 10.1016/j.biomaterials.2004.01.009

88. Ding PG, Wolff D, Pioch T, Staehle HJ, Dannewitz B. Relationship between microtensile bond strength and nanoleakage at the composite-dentin interface. Dent Mater. (2009) 25:135-41. doi: 10.1016/j.dental.2008.05.009

89. Monticelli F, Toledano M, Silva AS, Osorio E, Osorio R. Sealing effectiveness of etch-and-rinse vs self-etching adhesives after water aging: influence of acid etching and $\mathrm{NaOCl}$ dentin pretreatment. J Adhes Dent. (2008) 10:183-8.

90. Khosravi K, Ataei E, Mousavi M, Khodaeian N. Effect of phosphoric acid etching of enamel margins on the microleakage of a simplified all-in-one and a self-etch adhesive system. Oper Dent. (2009) 34:5316. doi: 10.2341/08-026-L

91. Nagpal R, Manuja N, Tyagi SP, Singh UP. In vitro bonding effectiveness of self-etch adhesives with different application techniques: a microleakage and scanning electron microscopic study. J Conserv Dent. (2011) 14:25863. doi: 10.4103/0972-0707.85805

92. Perdigão J, Monteiro P, Gomes G. In vitro enamel sealing of self-etch adhesives. Quintessence Int. (2009) 40:225-33.

93. Taschner M, Nato F, Mazzoni A, Frankenberger R, Krämer N, Di Lenarda R, et al. Role of preliminary etching for one-step self-etch adhesives. Eur J Oral Sci. (2010) 118:517-24. doi: 10.1111/j.1600-0722.2010.00769.x

94. Sato T, Nikaido T, Takagaki T, Baba Y, Vicheva M, Sato A, et al. Influence of primer contamination on the bonding interface of enamel pre-etched with phosphoric acid. Dent Mater J. (2021). doi: 10.4012/dmj.2020-367. [Epub ahead of print].

95. Halabi S, Matsui N, Nikaido T, Burrow MF, Tagami J. Effect of office bleaching on enamel bonding performance. J Adhes Dent. (2019) 21:16777. doi: 10.3290/j.jad.a42362

96. Tsuchiya S, Nikaido T, Sonoda H, Foxton RM, Tagami J. Ultrastructure of the dentin-adhesive interface after acid-base challenge. J Adhes Dent. (2004) 6:183-90.

97. Li N, Nikaido T, Takagaki T, Sadr A, Makishi P, Chen J, et al. The role of functional monomers in bonding to enamel: acidbase resistant zone and bonding performance. J Dent. (2010) 38:722-30. doi: 10.1016/j.jdent.2010.05.015

98. Waidyasekera K, Nikaido T, Weerasinghe DS, Ichinose S, Tagami J. Reinforcement of dentin in self-etch adhesive technology: a new concept. $J$ Dent. (2009) 37:604-9. doi: 10.1016/j.jdent.2009.03.021

99. Nikaido T, Weerasinghe DD, Waidyasekera K, Inoue G, Foxton RM, Tagami J. Assessment of the nanostructure of acid-base resistant zone by the application of all-in-one adhesive systems: super dentin formation. Biomed Mater Eng. (2009) 19:163-71. doi: 10.3233/BME-2009-0576

100. Sato T, Takagaki T, Matsui N, Hamba H, Sadr A, Nikaido T, et al. Morphological evaluation of the adhesive/enamel interfaces of two-step selfetching adhesives and multimode one-bottle self-etching adhesives. J Adhes Dent. (2016) 18:223-9. doi: 10.3290/j.jad.a36135

101. Sato T, Takagaki T, Ikeda M, Nikaido T, Burrow MF, Tagami J. Effects of selective phosphoric acid etching on enamel using "no-wait" self-etching adhesives. J Adhes Dent. (2018) 20:407-15. doi: 10.3290/j.jad.a41359

102. Li N, Nikaido T, Alireza S, Takagaki T, Chen JH, Tagami J. Phosphoric acidetching promotes bond strength and formation of acid-base resistant zone on enamel. Oper Dent. (2013) 38:82-90. doi: 10.2341/11-422-L

103. Mjör IA, Shen C, Eliasson ST, Richter S. Placement and replacement of restorations in general dental practice in Iceland. Oper Dent. (2002) 27:117-23.
104. de Assis C, Lemos C, Gomes J, Vasconcelos B, Moraes S, Braz R, et al. Clinical efficiency of self-etching one-step and two-step adhesives in NCCL: a systematic review and meta-analysis. Oper Dent. (2020) 45:598607. doi: 10.2341/19-185-L

105. Szesz A, Parreiras S, Reis A, Loguercio A. Selective enamel etching in cervical lesions for self-etch adhesives: a systematic review and meta-analysis. J Dent. (2016) 53:1-11. doi: 10.1016/j.jdent.2016.05.009

106. Fujiwara S, Takamizawa T, Barkmeier WW, Tsujimoto A, Imai A, Watanabe $\mathrm{H}$, et al. Effect of double-layer application on bond quality of adhesive systems. J Mech Behav Biomed Mater. (2018) 77:5019. doi: 10.1016/j.jmbbm.2017.10.008

107. Hirokane E, Takamizawa T, Kasahara Y, Ishii R, Tsujimoto A, Barkmeier WW, et al. Effect of double-layer application on the early enamel bond strength of universal adhesives. Clin Oral Investig. (2021) 25:90721. doi: 10.1007/s00784-020-03379-1

108. Loguercio AD, Muñoz MA, Luque-Martinez I, Hass V, Reis A, Perdigão J. Does active application of universal adhesives to enamel in self-etch mode improve their performance? J Dent. (2015) 43:1060-70. doi: 10.1016/j.jdent.2015.04.005

109. Cardenas AFM, Armas-Veja A, Rodriguez Villarreal JP, Siqueira FSF, Muniz LP, Campos VS, et al. Influence of the mode of application of universal adhesive systems on adhesive properties to fluorotic enamel. Braz Oral Res. (2019) 33:e120. doi: 10.1590/1807-3107bor-2019.vol33.0120

110. Imai A, Takamizawa T, Sai K, Tsujimoto A, Nojiri K, Endo H, et al. Influence of application method on surface free-energy and bond strength of universal adhesive systems to enamel. Eur J Oral Sci. (2017) 125:38595. doi: 10.1111/eos.12361

111. Shimatani Y, Tsujimoto A, Nojiri K, Shiratsuchi K, Takamizawa T, Barkmeier WW, et al. Reconsideration of enamel etching protocols for universal adhesives: effect of etching method and etching time. J Adhes Dent. (2019) 21:345-54. doi: 10.3290/j.jad.a42933

112. Yao C, Ahmed MH, Yoshihara K, Mercelis B, Parise Gré C, Van Landuyt KL, et al. Bonding to enamel using alternative enamel conditioner/etchants. Dent Mater. (2019) 35:1415-29. doi: 10.1016/j.dental.2019.07.022

113. Wong J, Tsujimoto A, Fischer NG, Baruth AG, Barkmeier WW, Johnson EA, et al. Enamel etching for universal adhesives: examination of enamel etching protocols for optimization of bonding effectiveness. Oper Dent. (2020) 45:80-91. doi: 10.2341/18-275-L

114. Baba Y, Sato T, Takagaki T, Vicheva M, Sato A, Ikeda M, et al. Effects of different tooth conditioners on the bonding of universal self-etching adhesive to enamel. J Adhes Dent. (2021). [Epub ahead of print].

115. Sato T, Takagaki T, Baba Y, Vicheva M, Matsui N, Hiraishi N, et al. Effects of different tooth conditioners on the bonding of universal selfetching adhesive to dentin. J Adhes Dent. (2019) 21:77-85. doi: 10.3290/j.jad. a41917

Conflict of Interest: The authors declare that the research was conducted in the absence of any commercial or financial relationships that could be construed as a potential conflict of interest.

Copyright (C) 2021 Sato, Takagaki, Hatayama, Nikaido and Tagami. This is an openaccess article distributed under the terms of the Creative Commons Attribution License (CC BY). The use, distribution or reproduction in other forums is permitted, provided the original author(s) and the copyright owner(s) are credited and that the original publication in this journal is cited, in accordance with accepted academic practice. No use, distribution or reproduction is permitted which does not comply with these terms. 